\title{
A ESPERA NO CENTRO CIRÚRGICO: PERCEPÇÃO DO FAMILIAR
}

\author{
Denise Teresinha Arnhold ${ }^{1}$, Paula Michele Lohmann², Luís Felipe Pissaia ${ }^{3}$, \\ Arlete Eli Kunz da Costa ${ }^{4}$, Claudete Moreschi ${ }^{5}$
}

\begin{abstract}
Resumo: Este trabalho possui tem por objetivo conhecer os principais sentimentos da família que espera em frente ao centro cirúrgico. Trata-se de um estudo descritivo, exploratório e transversal, com abordagem qualitativa, foi entrevistado oito familiares, sendo a maioria do gênero feminino, estes aguardavam na sala de espera do Centro Cirúrgico de um hospital de médio porte do interior do estado do Rio Grande do Sul. Obtiveram-se três temas: Percepção de quem aguarda o familiar que está no procedimento cirúrgico; Orientação recebida sobre o período da espera; $O$ que fez enquanto esperava para amenizar algum tipo de desconforto. O estudo apresenta um novo espaço de atuação para o enfermeiro que pode ser utilizado de forma a qualificar e potencializar a atenção de enfermagem em sala de espera por conferir visibilidade à gestão do cuidado de enfermagem nas instituições de saúde, todas as respostas ratificaram os anseios da família e do paciente no contexto da realização de um procedimento cirúrgico.
\end{abstract}

Palavras-chave: Centro Cirúrgico. Acolhimento. Humanização da assistência. Cuidado. Enfermagem.

\section{INTRODUÇÃO}

O Centro Cirúrgico (CC) é um lugar especial dentro de uma instituição hospitalar, por ser uma área restrita que presta assistência integral ao paciente

1 Enfermeira pela Univates. deniseta@universo.univates.br

2 Enfermeira. Mestre em Ambiente e Desenvolvimento. Docente da Univates. paulalohmann@univates.br

3 Enfermeiro. Mestrando em Ensino. Centro Universitário UNIVATES. lpissaia@universo.univates.br

4 Enfermeira. Doutora em Ambiente e Desenvolvimento. Docente da Univates. arlete.costa@univates.br

5 Enfermeira. Doutora em Ambiente e Desenvolvimento pela Univates. clau_moreschi@yahoo.com.br 
cirúrgico em todo o período pré, trans e pós-operatório, funcionando de forma ágil com uma variedade de processos paralelos. A planta física do CC busca proporcionar barreiras para amenizar a entrada de microrganismos e permanecendo de fácil acesso próximo a Unidade de Terapia Intensiva (UTI), unidade de internação cirúrgica e Pronto Socorro (PS). O ambiente do CC é composto por vários ambientes incluindo a sala de espera, sala de recuperação pós-anestésica, salas cirúrgicas, farmácia, expurgo, lavabo, arsenal, corredor, vestiário para paciente, vestiário masculino e feminino para funcionário, copa de lanche, rouparia, sala de guarda de equipamentos. As equipes atuantes no CC são as cirúrgicas, de anestesia, de enfermagem, de higiene e administrativa (SILVA; ALVIM, 2010).

Este setor é classificado em três áreas, a crítica, a semicrítica e a não crítica: Área crítica é composta por ambientes onde existe maior probabilidade de infecção e onde se realizam procedimentos variados. Área semicrítica são todos os compartimentos ocupados por pacientes com doenças infecciosas de baixa transmissibilidade e doenças não infecciosas. Já a área não crítica são todos os demais compartimentos não ocupados por pacientes, onde não se realizam procedimentos de risco (SILVA; ALVIM, 2010).

As pessoas que aguardam na sala de espera pelo seu familiar apresentam uma série de sentimentos como, ansiedade, coração apertado, sofrimento, medo, depressão, nervosismo. E neste período as pessoas se manifestam através de gestos como esfregar as mãos, balançar os pés, o olhar perdido e a inquietação de permanecer sentado ou andando para todos os lados (SALIMENA; ANDRADE; MELO, 2011).

A relação do paciente e do familiar com o ambiente de espera ao procedimento cirúrgico torna-se menos agressivo quando ele encontra neste espaço um momento de recriação. As brincadeiras e os objetos amenizam a ansiedade, dando espaço para a distração. Este ambiente lúdico em especial é muito importante, pois estará diminuindo o medo do estranho, tornando-o mais familiar (VEBER, 2010).

Para diminuir os sentimentos que se manifesta no momento em que a separação dos familiares acontece, a equipe deve realizar um momento de acolhimento do paciente e de sua família, buscando amenizar o sentimento de angústia. Para este relacionamento ser efetivamente terapêutico para ambos, muitas vezes a enfermagem deve colocar se no lugar do familiar empaticamente (FRIZON et al., 2011).

A equipe de enfermagem está presente em maior número e tempo em contato com o paciente, deve estar habilitada a confortar os familiares que aguardam na sala de espera. Em forma de acolhimento, escuta, dando orientações, informações sobre o quadro do indivíduo (SALIMENA; ANDRADE; MELO, 2011). 
Neste sentido, o principal objetivo deste estudo é conhecer os principais sentimentos da família que espera em frente ao centro cirúrgico.

\section{MÉTODO}

Trata-se de um estudo descritivo, exploratório e transversal, com abordagem qualitativa. Os sujeitos de pesquisa foram oito familiares de pacientes que aguardavam em frente ao centro cirúrgico de um hospital de médio porte do interior do Rio Grande do Sul.

Primeiramente os pesquisadores verificaram o consentimento da instituição hospital como campo de estudo, através de carta de anuência, obtendo aprovação para realização da pesquisa. A segunda etapa foi o contato com a enfermeira responsável pela unidade de CC, agendando os dias para a realização das entrevistas e o local que seria disponibilizado para os pesquisadores conversarem com os sujeitos da pesquisa.

Para tanto, a coleta de dados ocorreu nos meses de setembro e outubro de 2016, durante este período os pesquisadores visitaram a unidade em ocasiões aleatoriamente escolhidas. Neste sentido, a seleção dos familiares que aguardavam em frente ao CC era realizada no momento em conformidade com os critérios de inclusão e exclusão pré-estabelecidos no estudo.

Os critérios de inclusão eram: familiar que aguarda em frente ao centro cirúrgico; idade superior a 18 anos; que aceite participar da pesquisa; que apresente capacidade de responder as questões do estudo durante o período que aguarda o seu familiar sair da recuperação cirúrgica. Critérios de exclusão: Idade inferior a 18 anos; familiar que se recusar a participar da pesquisa; familiar que não estiver em condições psicológicas para responder.

Após a identificação dos sujeitos foram explicados os objetivos do projeto de pesquisa, bem como os critérios éticos que fundamentam o processo, convidando-os a participar do estudo. Em caso de aceite, os indivíduos eram convidados em espaço reservado cedido pela instituição hospitalar, onde a confidencialidade das informações pode ser preservada, induzindo a um ambiente acolhedor para o diálogo. Neste espaço os pesquisadores reforçavam os objetivos da pesquisa e os critérios éticos para sua realização, sendo neste momento assinado o Termo de Consentimento Livre e Esclarecido (TCLE) em duas vias.

As entrevistas foram realizadas individualmente através de um instrumento elaborado pelos pesquisadores contendo quatro questões norteadoras e caracterização dos informantes da pesquisa. Foram problematizadas as relações da família com o ambiente de espera do familiar submetido ao procedimento cirúrgico, além de reflexões quanto a: Qual a percepção da família que espera em frente ao Centro Cirúrgico? E como hipóteses questionamos que: $\mathrm{O}$ ambiente de espera do familiar que se submete à procedimento cirúrgico é fator de sentimentos de angústia para a família? A 
realização de acolhimento da família propicia um momento de tranquilização da espera pelo familiar?

Os momentos de diálogo tiveram duração média de 20 minutos, tendo seus áudios gravados e posteriormente transcritos na íntegra. A análise do conteúdo foram realizadas de acordo com a teoria proposta por Bardin (2011), onde foram organizados temas de acordo com as respostas das perguntas que se assemelhavam. Conforme preconizado pelos critérios éticos em pesquisa, os nomes próprios dos indivíduos foram substituídos por nomes de flores sorteados aleatoriamente e utilizados como codinome.

Todos os critérios éticos foram respeitados conforme previstos pela Resolução 466/2012 do Conselho Nacional de Saúde. No mesmo sentido o TCLE resguardará a propriedade intelectual dos dados e a divulgação pública dos resultados que será realizada no momento da apresentação oral do trabalho de conclusão de curso (TCC) e, posteriormente, publicação de artigos em periódicos científicos, ou ainda, apresentado em palestras, seminários ou congressos.

\section{RESULTADOS}

Conforme a análise das informações caracterizou-se os oito sujeitos pelo gênero, como a maioria sendo do sexo feminino, $75 \%$ e $25 \%$ do sexo masculino. A idade variou de 36 a 58 anos. Quanto ao grau de parentesco a maioria informou ser pai, mãe, filho, esposa ou sogra. E os procedimentos aos qual o familiar estava realizando no CC foram, 4 Colecistéctomias, 2 Cesarianas, 1 Schunt e 1 fratura de mão.

De acordo com os objetivos de pesquisa e relacionando-se às respostas emergiram três categorias temáticas: (1) Percepções de quem aguarda o familiar que está no procedimento cirúrgico; (2) Orientações recebidas sobre o período da espera; e (3) O que fez enquanto esperava para amenizar algum tipo de desconforto.

\subsection{Percepções de quem aguarda o familiar que está no procedimento cirúrgico}

Esta categoria procura demonstrar de que forma os familiares percebem o momento da espera do seu familiar e quais os sentimentos que afloram quando o familiar está sendo submetido ao tratamento cirúrgico. As maiorias dos entrevistados alegaram que o momento de aguardar na sala de espera em frente ao CC, foi um período de desinformação, de ansiedade e demora. Podemos destacar os seguintes relatos: "Ansiedade, espera" (Jasmim); "Passar horas sem informações do paciente" (Cravo).

$\mathrm{O}$ ambiente hospitalar possui vários fatores que contribuem para a ansiedade, que vai desde exposição da imagem, o processo de despersonalização que induz a uma prática de desumanização por parte da equipe de saúde. O grau 
de ansiedade do paciente pode influenciar no cancelamento do procedimento devido que este estresse altera o estado emocional e o funcionamento do sistema imunológico (COSTA et al., 2009).

Os procedimentos cirúrgicos dependendo do grau de complexidade podem ser acompanhados de anseios, dúvidas e medo. Isto acontece por falta de informações sobre os acontecimentos que sucedem em cada fase da cirurgia, e também pelas situações que a internação hospitalar pode proporcionar (SOUZA; SOUZA; FENILI, 2005).

Ao prestar assistência de enfermagem através de procedimentos seguros e baseados em boas práticas, o enfermeiro está promovendo uma ação mais humanizada, através de recursos humanos com habilidades técnicas (COSTA et al., 2009). Mesmo assim surgem estes sentimentos, conforme as falas: " $O$ tempo de espera, normalmente sem informações" (Rosa); "Demora" (Lírio); "A espera do familiar" (Violeta).

$\mathrm{Na}$ sala de espera para os pacientes e familiares apresentam sinais de ansiedade e medo devido situações que permeiam a realização e resultado dos procedimentos. Isto acontece devido o desconhecimento das etapas que o paciente passa no CC, pelo motivo que os acompanhantes não acompanham o paciente nos procedimentos que irão realizar (ALCÂNTARA et al., 2013).

Para Ivancko (2004), a sala de espera é fundamental para dar orientações, acolhimento, suporte e esclarecimento para amenizar a ansiedade e o medo e ainda aliviar a própria espera. Acredita-se que a enfermagem possa fornecer explicações corretas com linguagem acessível para a idade e ao nível de cognitivo do paciente para melhor entendimento da doença de forma realista e adequada, isto causa menos ansiedade e fantasias (ALCÂNTARA et al., 2013).

O período perioperatório envolve o espaço de tempo em que o paciente toma a decisão a submeter-se a tratamento cirúrgico e termina com uma avaliação do acompanhamento clinico em casa, após a cirurgia. A enfermagem tem papel importante nas orientações sobre o processo cirúrgico para o paciente e aos seus familiares ou acompanhantes, pois permite encarar essa situação com mais tranquilidade. Também estas orientações são indispensáveis para promoção e manutenção da saúde e além de oportunizar a participação do processo que envolve o tratamento e reabilitação(TENANI; PINTO, 2007). Neste mesmo sentido aparecem outras falas: "Falta de informação, agonia, desespero" (Orquídea); "A falta de informação" (Begônia); "Não tem nada" (Mosquitinho).

Em relação aos sentimentos foram destacados a ansiedade, angústia, nervosismo e medo como os principais. Como pode ser observado nas seguintes falas: "Saber que vai dar tudo certo" (Jasmim); "Ansiedade, angustia, agonia" (Cravo); "Tristeza, medo, insegurança" (Rosa); "Nervosismo" (Lírio).

A ansiedade é um estado emocional desconfortável que consiste no pressentimento do perigo, na atitude da espera e na desestruturação em meio à desproteção. A preocupação com o desconhecido, por não saber de fato como 
a pessoa se encontra no momento da cirurgia, por isso o estado emocional de cada familiar é entendido como singular (SALIMENA; ANDRADE; MELO, 2011). Ansiedade é uma reação emocional transitória que é caracterizada por sentimentos de apreensão, nervosismo e preocupação, isto se intensifica da forma como o familiar compreende a cirurgia (LIMA; SILVA; GENTILE, 2009). Conforme as falas que seguem: "Apreensivo" (Violeta); "Agonia, desespero" (Orquídea); "Angustia nervosismo" (Begônia); "A angustia, medo" (Mosquitinho).

$\mathrm{O}$ ato cirúrgico para o paciente consiste num dos momentos mais críticos do processo terapêutico, devido ao medo do desconhecido, a complexidade e risco do procedimento. $\mathrm{O}$ impacto que isso causa no indivíduo varia de paciente para paciente e também depende de vários fatores, como sexo, idade, estado físico, tipo de cirurgia e temor ao ambiente hospitalar (CHRISTÓFORO; CARVALHO, 2009).

Para o paciente com ansiedade diante do processo cirúrgico acaba sendo inevitável que o medo e a insegurança o acompanhem apresentando-se como uma ameaça, e não apenas à sua integridade física, mas também psíquica em virtude da ansiedade que pode gerar (COSTA et al., 2009).

\subsection{Orientações recebidas sobre o período da espera}

Para os familiares a categoria relaciona-se ao momento de espera onde recebe orientações sobre o procedimento ou do tempo que iram aguardar pelo familiar em frente ao CC. Os entrevistados relatam que muitas vezes não receberam orientações, ou se recebem é do próprio médico. Os seguintes relatos são: "Ainda não recebi nada, ninguém veio falar nada" (Jasmim); "Somente o médico me informou de como foi à cirurgia e que ficaria algumas horas na recuperação" (Cravo).

O cuidado de enfermagem inclui, preparo físico e emocional, orientação, avaliação e encaminhamento ao centro cirúrgico, com a finalidade de diminuir os riscos cirúrgicos e ainda promover a recuperação e evitar as complicações no pós-operatório (POSSARI, 2007). A assistência de enfermagem consiste em acompanhar o paciente desde sua internação e até a alta pós-cirúrgica, pelo motivo que a enfermagem fica atenta a todos as alterações que poderão surgir durante este período, tornando a recuperação segura e eficaz (ANDREU; DEGHI, 2009).

Na área da saúde os enfermeiros são os profissionais mais preparados para orientar pacientes e acompanhantes em relação ao seu tratamento e prevenção de agravos. No ambiente do CC isso inclui as orientações préoperatórias, que visam suavizar as questões conflitantes e preparar o paciente para o ato cirúrgico. Para isto devemos incluir a família no processo de comunicação e interagir com os familiares em todas as fases do processo cirúrgico, este é um fato que contribui para amenizar as tensões provenientes do sentimento de risco que envolve o procedimento cirúrgico (LIMA; SILVA; 
GENTILE, 2009). Conforme seguem algumas falas: "Depois de certo tempo o médico avisou que seria de 3 a 4 horas" (Rosa); "Não recebi informação" (Lírio); "Do médico" (Violeta); "Pela própria médica" (Orquídea); "Primeira à informação do médico, seria importante na internação" (Begônia); "Da enfermeira" (Mosquitinho).

$\mathrm{O}$ enfermeiro é o profissional central com o qual o paciente e familiar poderão contar e a quem irão se dirigir para todo e qualquer momento ou situação, tanto para obter informações, como solicitar ajuda a solução de problemas. A orientação é uma atividade comum para os profissionais de saúde, ao enfermeiro compete à educação em saúde do paciente, pois muitas vezes é ele quem clareia as informações fornecidas por outros profissionais (BASTOS; DUQUIA, 2007).

O enfermeiro tem a necessidade de compreender os problemas do paciente e de sua família, também suas dificuldades, duvidas anseios e ajudá-lo por meio de orientações desde o momento da decisão pela cirurgia e de reforçar as informações quando necessário. Pois certifica que os familiares quando bem orientados, eles demonstram suas inseguranças e fragilidades, isto repercute de forma favorável, tendo um relacionamento mais harmônico com a equipe e seus familiares internados e para o paciente o cuidado humanizado resulta em comportamento tranquilo (FONSECA; PENICHE, 2009).

O período pré-operatório consiste em identificar os possíveis distúrbios no paciente e reduzir os riscos cirúrgicos, este momento é de responsabilidade da equipe de enfermagem o preparo adequado do paciente para a cirurgia de acordo com o tipo e porte cirúrgico. O pré-operatório tem finalidade educar o paciente e sua família, explicando as rotinas, procedimentos, a chegada ao centro cirúrgico, e como cera feita o procedimento e sua recuperação após o procedimento, esclarecendo suas dúvidas e de sua família (DAIAN et al., 2010).

O enfermeiro em sua função atua encorajando os pacientes em forma de orientações sobre o processo cirúrgico que é essencial para o sucesso do tratamento, e para que aderem ao regime terapêutico e transforme se na principal fonte de informações necessárias para enfrentar o ato cirúrgico (FONSECA; PENICHE, 2009).

O pré-operatório é uma etapa muito importante para o paciente que encontra-se abalado pela doença e da internação cirúrgica a qual será submetido. A avaliação pré-operatória feita pelo enfermeiro fornece informações, verifica suas dúvidas e ajuda a solucionar os problemas através de uma assistência qualificada elaborada de um plano de cirurgia no período pré-operatório (PASSOS; SILVA; CARVALHO, 2010).

\subsection{O que fez enquanto esperava para amenizar algum tipo de desconforto}

Esses relatos mostram a forma que os familiares encontraram para manterem se calmos enquanto aguardavam em frente do CC, pelo seu ente querido que estivesse em procedimento cirúrgico. Os entrevistados relataram 
que rezavam para manterem se calmos, ficava no celular, confiar em Deus. Destaca se os seguintes relatos: "Rezar e confiar em Deus" (Jasmim); "Ficar paciente e ter pensamento positivos" (Cravo); "rezo, caminho de um lado para outro, converso com outras pessoas que também estão aguardando, navego na internet" (Rosa); "Ficar sentado" (Lírio); "Não pensar que a pessoa está num hospital" (Violeta); "Mexer no celular" (Orquídea); "Caminho de um lado para o outro, mas a ajuda do profissional técnico é muito importante" (Begônia); "Sentar e esperar" (Mosquitinho).

Destacam a importância das ações de enfermagem em sala de espera para lidar melhor com as questões pertinentes ao tratamento e hospitalização, indicando que essas atividades possibilitam a ampliação de comportamentos colaborativos, com interação social e de adaptação aos eventos provenientes do tratamento. Visam suporte emocional e proporcionar espaço de escuta, apoio, acolhimento e ludicidade aos pacientes e acompanhantes, com o objetivo de favorecer a exposição, elaboração e ventilação dos sentimentos relacionados aos procedimentos, doença e ao tratamento de forma geral (ALCÂNTARA et al., 2013).

\section{DISCUSSÃO}

O Centro Cirúrgico é definido como uma área de acesso restrito que pertence a um estabelecimento assistencial de saúde, a fim de proporcionar barreiras para impedir a entrada de micro-organismos, mantendo uma série de dependências interligadas como sala de preparo do paciente, corredor, sala de recuperação após anestésica, salas de procedimento cirúrgico, expurgo, lavabo, rouparia, farmácia, arsenal, sala para guardar material e equipamentos, banheiro para paciente, banheiro masculino e feminino para os funcionários e copa para lanches. A enfermagem neste ambiente atua na preparação da sala de cirurgia e na Comissão de Controle de Infecção nos Serviços de Saúde (CCISS) e na participação na assistência de enfermagem para o usuário no pré e pósoperatório imediato (SILVA; ALVIM, 2010).

O ambiente do CC em todos os seus aspectos, físico, psicológico e social, estes interferem no conforto e bem-estar do cliente, como dos profissionais que trabalham isto influencia na manutenção e na restauração de sua energia vital. A ação da enfermagem é fundamental na organização e na manutenção do ambiente, e tem o objetivo de colocar o cliente na melhor posição para que a natureza possa agir sobre ele. A intervenção destes profissionais proporciona o equilíbrio do ambiente para que o cliente consiga todas as suas energias para a sua recuperação (TENANI; PINTO, 2007).

A dinâmica do cuidado de enfermagem é muito voltada aos objetivos das ações, sendo as intervenções técnica para a recuperação do cliente, o cuidado, a demonstração de afeto, o toque e a conversa muitas vezes são restritas, devido que neste ambiente tem-se pouco tempo de convivência com o cliente, mas não quer dizer que não haja expressividade no cuidado. A enfermagem neste 
ambiente proporcione um cuidado ao cliente, no planejamento do setor, na delegação de ações, na previsão e na capacitação de sua equipe, visando sempre às melhorias no cuidado. A enfermeira toma as devidas providências para que os profissionais possam exercer as suas funções do modo mais eficiente, criando um ambiente favorável ao desenvolvimento de seu trabalho, para melhorar a qualidade da assistência que os clientes necessitam (SILVA; ALVIM, 2010).

Os aspectos do cuidado estão ligados ao corpo biológico, e com o ambiente físico e social que se evidencia no intrapessoal, valorizando a expectativa e o desejo no processo de cuidar. A dinâmica e a finalidade deste setor estão associadas à dificuldade da presença efetiva da enfermeira junto ao paciente neste espaço, mas os cuidados de enfermagem que não se expressam no procedimento técnico. Mas toda a ação realizada pela enfermeira tem como foco a preocupação, o cuidado ao cliente para recuperação plena, este cuidado ocorre no CC. O cuidado construído no encontro entre a enfermeira com o cliente, nem sempre é construído na relação face a face com o cliente, e sim uma série de ações que a mesma realizada que caracteriza sua pré-ocupação e garantindo-lhe conforto e bem-estar (COSTA et al., 2009).

A enfermagem tem uma preocupação constante com a humanização do cuidado, para elas muitas vezes são dificuldades, isto está relacionado ao número reduzido de enfermeiros para assistência. O enfermeiro de CC enfrenta uma serie de conflito e dificuldade quando a administração das instituições de saúde não compreende a importância da atuação do enfermeiro na assistência ao paciente cirúrgico no período perioperatório, com isto proporciona um desvio da sua função assistencial para a gerencial. A enfermagem deve ter a sua equipe bem treinada e qualificada, para oferecem a melhor assistência para o cliente, e também a enfermagem deve estar constantemente presente na sala de recuperação pós anestesia (SRPA) sendo indispensável para desenvolver uma assistência de qualidade e poder atuar na prevenção das complicações (JUNIOR et al., 2012).

A enfermagem busca pela qualidade de saúde que é definida como um conjunto de atributos que inclui excelência profissional, uso eficiente de materiais, diminuindo risco ao paciente e aumentando grau de satisfação por parte do usuário, considerando os valores sociais existentes. A qualidade não deve ser somente considerando os aspectos técnicos, e sim para as preferências do usuário e da sociedade. Para melhorar a qualidade da assistência à saúde os hospitais estão implantando a acreditação hospitalar sendo uma forma de avaliação das organizações de saúde (PASSOS; SILVA; CARVALHO, 2010).

A enfermagem tem um olhar ampliado em relação à família e ao paciente, tendo como importante a humanização da assistência ao paciente cirúrgico e à família, como estratégia a interação, orientação e comunicação. Também observa-se que ambos necessitam além da competência técnica, um apoio emocional. A equipe de enfermagem tem condições de observar e intervir e orientar para minimizar essa situação de ansiedade e medo (POSSARI, 2007). 
O estresse gerado na vida do ser humana em ambientes do CC pode causar reações no organismo da pessoa, como estímulos estressores. Isto pode acontecer devido ser um local estranho, desconhecido, angustiante, isto pode estar consumindo a reserva de energia de vida do cliente, podendo estar se prejudicando no momento da melhora da recuperação do mesmo. Os seres humanos produzem respostas caracterizadas por alterações fisiológicas, que por vez causa modificações na estrutura orgânica do organismo. Estas respostas são manifestações de adaptação do corpo, e de mecanismo de defesa contra o estresse, como perturbações nervosas ou emocionais, hipertensão arterial, alergias, problemas renais (RODRIGUES et al., 2009).

A emoção tem efeito direto ao estresse e podendo altera a função imune. Por isso quando o paciente for submetido ao procedimento cirúrgico o emocional se altera, podendo influenciar o tipo e a quantidade de anestesia administrada, pelo anestesista. E quando o paciente apresentar se ansiosos, estressado provavelmente nestes casos terá mais dor pós-operatória devido à redução da função imune. O procedimento cirúrgico constitui uma situação de estresse que envolve o paciente, sua família, o cirurgião, a equipe de enfermagem e também as equipes de anestesia. Os pacientes por vez desenvolvem sintomas estressores como emoções, medo, angústia, ansiedades, fantasias, em relação ao procedimento, por terem medo da morte(FRIZON et al., 2011).

Quando o estresse chega ao extremo o paciente começa a oscilar entre momentos de bem-estar e tranquilidade e momentos de desconforto, cansaço e ansiedade. Nestes casos deve haver o alívio para o estresse por meio da remoção dos estressores ou enfrentamento do estresse. Em momentos como estes a enfermagem deve estar ao lado do cliente orientando, tranquilizando-o e se colocar à disposição (SOUZA; SOUZA; FENILI, 2005).

$\mathrm{O}$ estresse para o indivíduo pode estar causado uma série de doenças, sendo considerado um problema desgastante para o organismo. Por muitas vezes estar submetido a procedimentos complicados, que irritam, e muitas vezes que interferem na qualidade de vida. Para a equipe de enfermagem o estresse também está ligado ao ambiente do CC devido ser um ambiente complexo do hospital, e onde, as atividades são desenvolvidas em um clima de tensão, pela existência de procedimentos estressantes, por muitas vezes gera ansiedade, e pela gravidade dos pacientes, pela complexidade dos procedimentos anestésicos e cirúrgicos. A equipe de enfermagem do centro cirúrgico se depara frequentemente com situações difíceis, sob intensa pressão, estas situações podem interferir na vida desses profissionais, prejudicando a saúde e por muitas vezes pode repercutindo no desempenho das atividades laborais (AFONSO, 2012).

Para os familiares que aguardam na sala de espera do centro cirúrgico pelo seu familiar, esta situação gera certos sentimentos, inquietações, neste ambiente tem-se a necessidade de dar atenção aos sentimentos do familiar que aguarda na sala de espera pelo seu ente querido. O enfermeiro deve dar uma 
atenção não apenas ao paciente, mas também para a família que vivencia a situação de doença. A atenção da enfermagem não mais esta só voltada apenas para o cuidado do paciente e sim também para os cuidados com os familiares (SALIMENA; ANDRADE; MELO, 2011).

Para a enfermagem as experiências das famílias que passam por situação em que o seu familiar esteja em sofrimento, este momento é de suma importância para um bom planejamento da assistência, pois estará mais instrumentalizado para o cuidado. Pois a presença da família reduz o mínimo possível às cicatrizes emocionais, ajuda para a melhoria no tratamento do doente e no bem-estar, tendo também como uma nova forma de trabalho para a enfermagem. O enfermeiro ao saber se relacionar e tem uma comunicar adequada, isto é essencial para o processo terapêutico, pois o mesmo sabe que com a comunicação consegue se vários dados importantes para o tratamento do paciente. Enquanto o familiar aguarda na sala de espera, o enfermeiro tem a finalidade de proporcionar para que este indivíduo consiga se sentir acolhido, ouvido, digno e reconhecido (POSSARI, 2007).

O período perioperatório começa no momento em que o cliente toma a decisão de realizar o procedimento cirúrgico e termina com uma avaliação no ambiente clínico ou em casa após a cirurgia. É muito importante para o cliente como para os seus familiares ou acompanhantes estarem bem orientados sobre o processo cirúrgico, pois será de suma importância para a promoção, manutenção da saúde, recuperação e tratamento do cliente, com isto os mesmos permitem encarar essa situação com mais tranquilidade (SALIMENA; ANDRADE; MELO, 2011).

O paciente ao sair de casa vive momentos de ansiedades em relação ao procedimento, a internação contribui para o sentimento de ruptura com a vida diária e a perda da autonomia. Podendo implicar numa série de sentimentos de desconforto, propiciando o processo de despersonalização, muito comum em grandes períodos de internação (CHRISTO; TRAESEL, 2009).

Um estudo mostra que é indispensável que a família e o paciente sejam informados com detalhes do funcionamento de todos os procedimentos e também sua finalidade, para que possam aderir e colaborar mais com o tratamento. Para isso é importante à realização de intervenções lúdicas que são fundamentais para que possam compreender o processo de adoecimento pelo qual estão passando. O paciente e familiar na sala de espera apresentam sofrimento psíquico e necessitam de alguém para compartilhar este momento de espera. Para este momento a escuta de enfermagem pode refletir de forma de forma positiva, proporcionando alivio para o procedimento e ameniza o desgaste físico e emocional ali manifestado (POTTER; PERRY, 2009).

Um estudo realizado com as intervenções lúdicas são as principais realizadas na sala de espera com o paciente, possibilita a um momento de ludicidade e descontração, este momento ajuda diminuir a ansiedade e o medo (KRUSE et al., 2009). 
A escuta de enfermagem no hospital é qualificada e diferenciada que atua para minimizar a angustia e ansiedade, possibilitando a amenizar a vivencia dolorosa. Esta escuta dá-se de forma verbal e não verbal através de palavras, gestos e do brincar, isto para que os pacientes possam expressar seus sentimentos, para tirar suas dúvidas e dar significado aos acontecimentos, tornando se sujeitos ativos diante do seu processo de saúde e doença (FERNANDES; PENICHE, 2015).

A escuta possibilita a expressão dos sentimentos e emoções que causam desconforto, permitindo a elaboração das vivencias dolorosas e angustiantes. O momento da escuta é crucial para possibilitar o paciente a expressar os sentimentos e vivencias referentes à doença e ao tratamento, podendo favorecer a manifestação dos medos, temores e angustias (FRIZON et al., 2011).

O cuidado com o paciente vai além das ações técnicas, a assistência de enfermagem oferece ao paciente uma compreensão completa sobre a cirurgia e preparo físico e psicológico para a intervenção cirúrgica, esta é uma atividade de promoção, manutenção da saúde, prevenção de complicações e redução do risco cirúrgico, esses são aspectos positivos para o paciente. Para que o paciente sinta se seguro deve haver um bom relacionamento com a equipe de enfermagem, pois é de extrema importância e garantia do sucesso está associada que é atendida pela demanda física, emocional e social do paciente (SANTANA; OLIVEIRA, 2015).

O sentimento de medoé caracterizado por uma perturbação, preocupação com a ideia de um perigo real ou aparente, esse distúrbio emocional é provocado por ameaça real ou aparente ou pela presença de algo perigoso ou estranho. $\mathrm{O}$ ambiente hospitalar promove medo no paciente cirúrgico, modificando os costumes e hábitos das pessoas, que não sabem como agir, por isto dependem dos profissionais para as atividades da vida diária, os sentimentos de solidão, medo, nervosismo e insegurança fazem com que busquem nos profissionais de enfermagem não apenas a cura e também segurança e afeto (BARRETO; DEON; GREGOLETI, 2012).

Os sentimentos negativos como nervosismo, medo, estresse, ansiedade, são os sentimentos identificados nos pacientes submetidos a procedimentos cirúrgicos, isso pode afetar no resultado da intervenção cirúrgica. Por isso o enfermeiro desenvolve o acolhimento e as orientações aos pacientes e familiares, para minimizar as consequências que podem repercutir na qualidade de vida após a cirurgia (PASSOS; SILVA; CARVALHO, 2010).

\section{CONSIDERAÇÕES FINAIS}

Através desta pesquisa chega-se à conclusão que cabe ao enfermeiro orientar e sanar as dúvidas dos familiares. O enfermeiro e os demais membros da equipe de saúde devem estabelecer interação e vínculo com os familiares, pois eles também necessitam ser assistidos. Desta maneira será promovida 
a integralidade da assistência, com a ajuda de toda a equipe. Esta forma da equipe agir ameniza não só a ansiedade, mas também ao aumento da confiança, a cooperação e aceitação do diagnóstico e do tratamento.

A atuação do enfermeiro na sala de espera tem-se mostrado de forma atenciosa, solidária, estabelecendo uma relação de vínculo e amenizando o sentimento que são expressos por medo, ansiedade e nervosismo, que se intensificam durante a permanência no centro cirúrgico. Por isso é de suma importância a atuação do enfermeiro, pois o mesmo oferece suporte emocional durante todo este período.

É fundamental a participação do enfermeiro por ter um olhar holístico ao prestar assistência ao paciente e o familiar no período Peri operatório. A realização do acolhimento na sala de espera é um caminho importante para a interação e o alcance da segurança e confiança do acompanhante junto ao profissional, mediante orientações quanto ao pré-operatório, transoperatório, ato anestésico e os cuidados pós-operatórios.

\section{REFERÊNCIAS}

AFONSO, Rosa M. L. Ludodiagnóstico: investigação clínica através do brinquedo. Porto Alegre: Artmed. 2012.

ALCÂNTARA, Tainara V. et al. Intervenções psicológicas na sala de espera: estratégias no contexto da Oncologia Pediátrica. Rev. SBPH, v. 16, n. 2, Rio de Janeiro dez. 2013

ANDREU, José M.; DEGHI, Larissa P. Enfermagem perioperatória: considerações gerais sobre a temática. In: Mamagutti W, Bonfim IM. (Orgs). Enfermagem em centro cirúrgico: atualidades e perspectivas no meio ambiente cirúrgico. São Paulo: Martinari, 2009.

BARDIN, Laurence. Análise de Conteúdo. Lisboa, Portugal; Edições 70, LDA, 2011.

BARRETO, Jorgiana B. M.; DEON, Thais M. P.; GREGOLETI, Viviane. Percepção de familiares dos pacientes oncológicos que frequentam o Hospital Universitário Santa Terezinha de Joaçaba-SC sobre a psico - oncologia. Unesco \& Ciência, v. 3, n. 1, p. 7584, 2012.

BASTOS, João L. D.; DUQUIA, Rodrigo P. Um dos delineamentos mais empregados em epidemiologia: estudo transversal. Scientia Medica, Porto Alegre, v.17, n.4, p.229232, 2007.

CHRISTO, Zuriel M.; TRAESEL, Elisete S. Aspectos Psicológicos do Paciente Oncológico e a Atuação da Psico-Oncologia no Hospital. Disciplinarum Scientia, v. 10, n. 1, p. 75-87, 2009. 
CHRISTÓFORO, Berendina E. B.; CARVALHO, Denise S. Cuidados de enfermagem realizados ao paciente cirúrgico no período pré-operatório. Rev Esc Enferm USP [internet]. v. 43, n. 1, p. 14-22, 2009.

COSTA, Roberta et al. O legado de Florence Nightingale: uma viagem no tempo. Texto Contexto Enferm. Florianópolis, v.18, n.4, p.661-9, 2009.

DAIAN, Márcia R. et al. Estresse em cirurgias de grande porte. Rev Med Minas Gerais, v.20, n.4, p.490-499, 2010.

FERNANDES, Hellen M. L. G.; PENICHE, Aparecida C. G. Percepção da equipe de enfermagem do Centro Cirúrgico acerca da Acreditação Hospitalar em um Hospital Universitário. Rev Esc Enferm USP, v.49, p.22-28, 2015.

FONSECA, Rosa M. P.; PENICHE, Aparecida C. G. Enfermagem em centro cirúrgico: trinta anos após criação do Sistema de Assistência de Enfermagem Perioperatória.

Acta Paul Enferm, v.22, n.4, p.428-33, 2009.

FRIZON, Gloriana et al. Familiares na sala de espera de uma unidade de terapia intensiva: sentimentos revelados. Rev. Gaúcha Enferm, Porto Alegre (RS), v. 32, n.1, p.72-8, 2011.

IVANCKO, Silvia M. E o tratamento se inicia na Sala de Espera... In: Angerami - Camon, V. A. (org.). Atualidades em Psicologia da Saúde. São Paulo: Thomson Learning. 2004.

JUNIOR, Aderson L. C. et al. Preparação psicológica de pacientes submetidos a procedimentos cirúrgicos. Estudos de Psicologia, Campinas, v.29, n.2, p.27-284, 2012.

KRUSE, Maria H. L. et al. Orientação pré-operatória da enfermeira: lembranças de pacientes. Rev Eletr Enferm [Internet]. v. 11, n. 3, p. 494-500, 2009.

LIMA, Fabiano B.; SILVA, Jorge L. L.; GENTILE, Angelina C. Relevância da comunicação terapêutica na amenização do estresse de cliente em pré-operotório: cuidados através de orientações. Informe-se em promoção da saúde, v.3, n.2.p.17-18, 2007.

PASSOS, Juciane B.; SILVA, Elizamar L.; CARVALHO, Mércia M. C. Estresse no centro cirúrgico: uma realidade dos profissionais de enfermagem. Rev Pesq Saúde, v.11, n.2, p.35-38, 2010.

POSSARI, João F. Centro cirúrgico: planejamento, organização e gestão. 3. ed. São Paulo: Iátria, 2007.

POTTER, Patrícia A.; PERRY, Anne G. Fundamentos de enfermagem. 7. ed. Rio de Janeiro: Elsevier, 2009.

RODRIGUES, Andréia D. et al. Sala De Espera: Um Ambiente Para Efetivar A Educação Em Saúde. Vivências, v. 5, n. 7, p. 101-106, 2009. 
SALIMENA, Anna M. O.; ANDRADE, Maura P.; MELO, Maria C. S. C. Familiares na sala de espera do centro cirúrgico: sentimentos e percepções. Cienc Cuid Saude, v.10, n.4, p.773-780, 2011.

SANTANA, Camila A.; OLIVEIRA, Célia G. E. Assistência de enfermagem na prevenção de infecções de sítio cirúrgico: uma revisão integrativa da literatura. Rev. Eletrôn. Atualiza Saúde, Salvador, v.1, n.1, p.76-88, 2015.

SILVA, Denise C.; ALVIM, Neide A. T. Ambiente do Centro Cirúrgico e os elementos que o integram: implicações para os cuidados de enfermagem. Rev Bras Enferm. Brasília, v. 63, n. 3, p. 427-34, 2010.

SOUZA, Aline A.; SOUZA, Zelita C.; FENILI, Rosangela M. Orientação pré-operatória ao cliente: uma medida preventiva aos estressores do processo cirúrgico. Revista Eletrônica de Enfermagem, v. 7, n. 2, p. 215-220, 2005.

TENANI, Ana C.; PINTO, Maria H. A importância do conhecimento do cliente sobre o enfrentamento do tratamento cirúrgico. Arq Ciênc Saúde [Internet]. v. 14, n. 2, p. 8591, 2007.

VEBER, Fernanda S. A influência da atividade lúdica sobre a ansiedade da criança durante o pré-operatório no centro cirúrgico ambulatorial. Jornal de Pediatria, v. 86, n. 3, p. 209-214, 2010. 